\title{
Outlet strut fracture of Björk-Shiley convexo concave heart valves: the UK cohort study
}

\author{
R Z Omar, L S Morton, D A Halliday, E M Danns, M T Beirne, W J Blot, K M Taylor
}

\begin{abstract}
Objective-To investigate the risk of outlet strut fracture (OSF) in Björk-Shiley convexo concave (BSCC) valves in relation to patients' clinical and valve characteristics.

Design-A cohort of 2977 patients with 3325 valves with a follow up of 18 years.

Setting-38 cardiac implantation centres in the UK.

Results-56 OSF events were reported with 43 occurring in mitral and 13 in aortic valves. The overall OSF rate was $0.17 \%$ year. No dominant clinical factor of risk was found, but multiple regression analysis identified age, body surface area, valve size, shop order fracture rate, and manufacturing period as risk factors for OSF. A 4\% (95\% confidence interval (CI) $2 \%$ to $6 \%$ ) decrease in the risk of OSF was observed for each advancing year of age and a fivefold (95\% CI 2 to 13) increase in risk for a $0.5 \mathrm{~m}^{2}$ increase in body surface area. The association between the risk of OSF and valve size was not constant over time. Excess risks among $31 \mathrm{~mm}$ and $33 \mathrm{~mm}$ sizes (mainly mitral valves) decreased over time while that for $23 \mathrm{~mm}$ (almost all aortic valves) increased. The risk of OSF increased by $40 \%$ (95\% CI $20 \%$ to $50 \%$ ) for a unit increase in the fracture rate of other valves in the same batch. For valves manufactured during 1981 to 1984 the risk of OSF was 4 (95\% CI 2 to 12) times greater than for valves manufactured before 1981 .

Conclusions-The OSF rates for $60^{\circ}$ BSCC valves observed in the UK are the highest among all monitored populations. The changing patterns of mitral and aortic valve OSF rates over time observed in this study have not been identified previously and highlight the need for continued monitoring of patients with the BSCC valve.

(Heart 2001;86:57-62)
\end{abstract}

Keywords: cohort studies; heart valves; outlet strut fracture

Björk-Shiley convexo concave (BSCC) prosthetic heart valves ${ }^{1}$ were implanted worldwide from 1978 until their withdrawal from the market by the manufacturer (Shiley Inc, Irvine, California, USA) in 1986 following reports of the valves' outlet strut fracture (OSF). This event results in the escape of the valve's tilting disc into the circulation generally resulting in the patient's death. OSFs have continued to occur in recent years and remain a concern for approximately 35000 patients worldwide with non-explanted BSCC valves. Important risk factors for OSF identified in previous studies include valve position, size, opening angle, manufacturing period, fracture rate in a batch (shop order) of valves produced, welder identity, and patient's age. ${ }^{2-9}$ These findings have enabled the development of guidelines for patients and their clinicians regarding considerations for elective explantation of the valve. ${ }^{10}$ However, it is not possible to conclude that these factors alone determine the risk of OSF with some events occurring outside of these parameters.

Investigation of OSF risks in relation to clinical factors has been limited. ${ }^{35}$ This paper describes a nationwide cohort study of 2977 patients with BSCC heart valves in the UK with 3325 implants and a follow up period of 18 years. A broad range of patient factors (for example, cardiac rhythm, arterial blood pressure, and left ventricular function) that might influence opening and closure of the valve prosthesis were investigated in relation to the risk of OSF. In addition valve characteristics previously identified as risk factors were examined.

\section{Methods}

IDENTIFICATION OF PATIENTS

Thirty eight cardiac surgical centres in the UK that had implanted BSCC valves were identified from the manufacturer's shipment records, and their hospital records were reviewed. A list of all patients with prosthetic valves implanted during 1979 to 1986 was compiled from the centres and patient records were examined to establish the valve type. Additionally, information from patients or relatives, MedicAlert Foundation, London, and implant cards returned to the manufacturer by the implantation centres were reviewed. Patients were confirmed to have BSCC valves only it at least two independent sources verified the valve type or if the type was confirmed through $x$ ray.

ABSTRACTION OF CLINICAL DATA

Information was abstracted from patients' clinical records using a standardised abstraction form. Where records were missing from the cardiac surgical centre, information was requested from the patient's general practitioner or the Family Health Service Authority. Extensive information relating to the BSCC valve implantation surgery covering pre-, periand postoperative periods was abstracted.
Correspondence to:

Sister Morton

lmorton@ic.ac.uk

Accepted 3 April 2001 


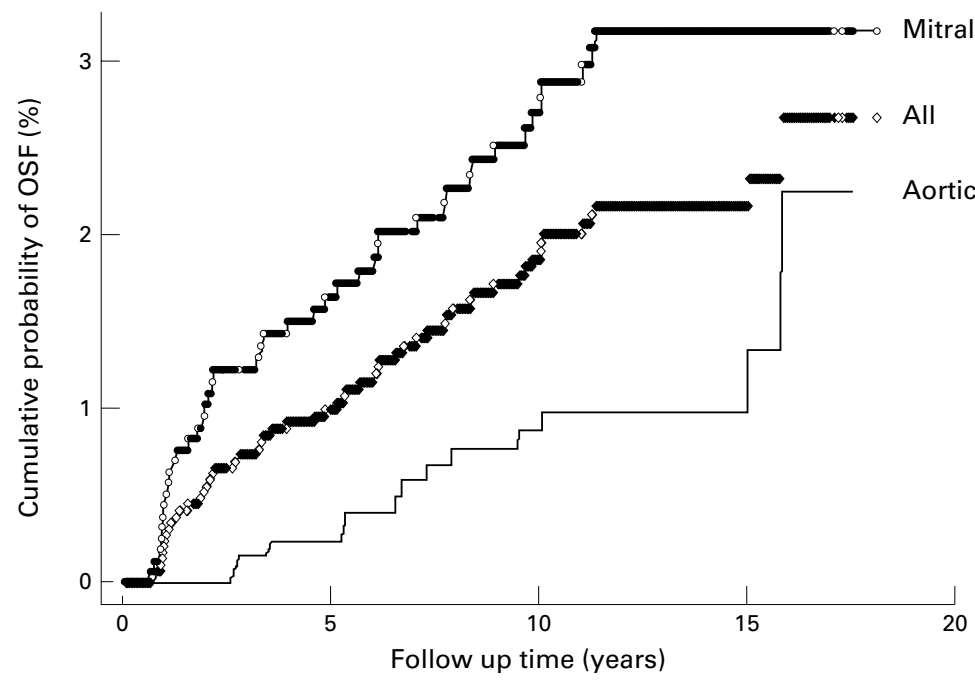

Figure 1 Cumulative probability of outlet strut fracture (OSF) by valve position.

INFORMATION ON VALVE CHARACTERISTICS

Information on valve characteristics was obtained from the manufacturer's research database for valves with complete serial numbers. For valves with incomplete or missing serial numbers information only on valve size was available from clinical records. Since $60^{\circ}$ BSCC valves welded before 1981 have been reported to be at a lower risk of fracture, ${ }^{689}$ manufacturing dates were grouped into two time periods: before 1981, and 1981 to 1984 . Welders were grouped into low, medium, and high risk groups following the classification in the guidelines of the Bowling Pfizer supervisory panel. ${ }^{10}$ Valves with no recorded welder identity were placed in a separate category. The

Table 1 Relative risk of outlet strut fracture (OSF) in Björk-Shiley convexo concave heart valves for demographic and manufacturing characteristics based on univariate Cox models

\begin{tabular}{|c|c|c|c|c|}
\hline Variable & $n$ OSF $/ n$ at risk & Relative risk & $95 \% C I$ & $p$ Value \\
\hline \multicolumn{5}{|l|}{ Age at implantation (years) } \\
\hline$<50$ (baseline) & $30 / 1027$ & 1.0 & - & $<0.001$ \\
\hline $50-59$ & $21 / 1107$ & 0.7 & 0.4 to 1.2 & \\
\hline$\geqslant 60$ & $5 / 1160$ & 0.2 & 0.1 to 0.4 & \\
\hline Sex & & & & 0.27 \\
\hline Male (baseline) & $27 / 1411$ & 1.0 & - & \\
\hline Female & $29 / 1882$ & 0.7 & 0.4 to 1.3 & \\
\hline Missing data & $0 / 1$ & & & \\
\hline \multicolumn{5}{|l|}{ Valve characteristics } \\
\hline Valve size (mm) & & & & $<0.001$ \\
\hline$\leqslant 21$ (baseline) & $1 / 356$ & 1.0 & - & \\
\hline 23 & $7 / 452$ & 5.3 & 0.6 to 42.9 & \\
\hline 25 & $1 / 468$ & 0.8 & 0.1 to 12.0 & \\
\hline 27 & $6 / 506$ & 4.1 & 0.5 to 34.4 & \\
\hline 29 & $14 / 700$ & 7.3 & 1.0 to 55.3 & \\
\hline 31 & $22 / 697$ & 12.3 & 1.7 to 91.4 & \\
\hline 33 & $5 / 112$ & 20.2 & 2.4 to 173.1 & \\
\hline Missing data & $0 / 3$ & & & \\
\hline Valve position & & & & 0.001 \\
\hline Aortic (baseline) & 13/1461 & 1.0 & - & \\
\hline Mitral & $43 / 1827$ & 2.8 & 1.5 to 5.3 & \\
\hline Tricuspid & $0 / 6$ & & & \\
\hline Manufacturing period ${ }^{\star}$ & & & & $<0.001$ \\
\hline Before 1981 (baseline) & $4 / 757$ & 1.0 & - & \\
\hline $1981-1984$ & $52 / 2365$ & 4.8 & 1.7 to 14.3 & \\
\hline Missing data & $0 / 72$ & & & \\
\hline Welder group ${ }^{\star}$ & & & & $<0.001$ \\
\hline Low risk (baseline) & $11 / 1085$ & 1.0 & - & \\
\hline Intermediate risk & $16 / 518$ & 2.9 & 1.4 to 6.4 & \\
\hline High risk & $22 / 751$ & 2.9 & 1.4 to 5.9 & \\
\hline Missing data & $7 / 840$ & 0.8 & 0.3 to 2.0 & \\
\hline Shop order fracture rate ${ }^{\star} \dagger$ & $56 / 3194$ & 1.5 & 1.4 to 1.7 & $<0.001$ \\
\hline
\end{tabular}

${ }^{\star}$ Based on 3194 valves with complete serial numbers; $†$ For continuous variable, the number listed is the number of strut fractures among patients for whom the value of the variable is known. shop order fracture rate was calculated for each valve as the percentage of other valves in the same batch or the shop order for which OSF has been notified to the manufacturer.

PATIENT FOLLOW UP AND DEFINITION OF OSF Patients were followed up from the date of implantation surgery until the occurrence of OSF, BSCC valve explantation surgery, death, emigration, last date known to be alive, or 31 July 1997, whichever came first. The vital status of patients was traced through the Office of National Statistics and the Central Services Agency, and copies of the death certificates for all traced deceased patients were obtained. An OSF event was recorded as such only if there was supporting documentation-namely, a postmortem report, a metallurgical report on an explanted BSCC valve, or a clear statement on the death certificate.

An attempt was made to identify unreported OSFs and to estimate the potential degree of under reporting in the UK. All death certificates and available postmortem reports were reviewed. For patients without postmortem reports, hospital records and general practitioner notes were examined to extract further information on circumstances surrounding death including health of the patient before death, whether the death was expected, and whether it was witnessed. Deaths with insufficient information recorded on the certificate for accurate assessment of the cause and with inadequate information on surrounding circumstances were classified according to the possibility of whether the death was related to an OSF by two consultant cardiothoracic surgeons working independently. This classification was based on the recorded cause and place of death (details provided in the appendix).

\section{STATISTICAL ANALYSIS}

The valve was used as the basic unit in all statistical analyses. Annual incidence rates of OSF were estimated by dividing the observed numbers of OSF by the follow up time of the valves. Relative risks (RR) of OSF were estimated using Cox's proportional hazards regression models. ${ }^{11}$ A backward elimination procedure ${ }^{12}$ was used to select the variables in the multiple regression model. Likelihood ratio tests were used to assess significance. The statistical software STATA (Stata Corporation, College Station, Texas, USA) was used for all statistical analyses.

\section{Results}

Data for 32838 person years were accumulated during the follow up of the cohort with a median follow up time of 12.5 years (range 1 day to 18 years). Complete serial numbers were available for $97 \%$ of the valves and follow up was complete for $97 \%$. There were 3295 valves with a $60^{\circ}$ and 30 valves with a $70^{\circ}$ opening angle. Since influence of clinical characteristics on OSF may be different for children, 31 valves implanted in patients less than 16 years of age were excluded from the analyses. No OSFs were reported in this group. 
Table 2 Relative risk of OSF in relation to clinical characteristics from Cox model adjusted for age

\begin{tabular}{|c|c|c|c|}
\hline & $n \mathrm{OSF} / \mathrm{n}$ at risk & Relative risk & $95 \% C I$ \\
\hline \multicolumn{4}{|l|}{ Preoperative variables } \\
\hline Body surface area $\left(\mathrm{m}^{2}\right)$ & $34 / 1856$ & 4.9 & 2.0 to 11.8 \\
\hline Pulse (per 10 beats/min) & $42 / 2393$ & 0.8 & 0.7 to 1.0 \\
\hline \multicolumn{4}{|l|}{ Rhythm } \\
\hline Sinus rhythm/regular rhythm (baseline) & $21 / 1098$ & 1.0 & - \\
\hline Atrial fibrillation/abnormal rhythm & $21 / 1197$ & 1.3 & 0.7 to 2.4 \\
\hline Unknown & $14 / 996$ & & \\
\hline Systolic arterial blood pressure (per $10 \mathrm{~mm} \mathrm{Hg}$ ) & $42 / 2438$ & 0.9 & 0.8 to 1.0 \\
\hline Diastolic arterial blood pressure (per $10 \mathrm{~mm} \mathrm{Hg}$ ) & $42 / 2433$ & 1.0 & 0.8 to 1.2 \\
\hline \multicolumn{4}{|l|}{ Pulmonary artery wedge pressure $(\mathrm{mm} \mathrm{Hg})$} \\
\hline Normal (baseline) & $4 / 192$ & 1.0 & - \\
\hline Raised & 9/395 & 1.3 & 0.4 to 4.3 \\
\hline Highly raised & $17 / 655$ & 1.5 & 0.5 to 4.5 \\
\hline Not recorded & $26 / 2052$ & & \\
\hline Left ventricular systolic pressure $(\mathrm{mm} \mathrm{Hg})$ & $32 / 1593$ & 0.8 & 0.7 to 0.9 \\
\hline \multicolumn{4}{|l|}{ Left ventricular end diastolic pressure $(\mathrm{mm} \mathrm{Hg})$} \\
\hline Normal (baseline) & $20 / 705$ & 1.0 & - \\
\hline Raised & $9 / 516$ & 0.7 & 0.3 to 1.4 \\
\hline Highly raised & $2 / 225$ & 0.4 & 0.1 to 1.5 \\
\hline Not recorded & $25 / 1848$ & & \\
\hline \multicolumn{4}{|l|}{ Ejection fraction/left ventricular function } \\
\hline Normal & $20 / 1194$ & 1.0 & - \\
\hline Moderate/severe & $7 / 407$ & 1.2 & 0.5 to 2.8 \\
\hline Not recorded & $29 / 1693$ & & \\
\hline \multicolumn{4}{|l|}{ Gradient pressure across the valves $(\mathrm{mm} \mathrm{Hg})^{\star}$} \\
\hline Normal (baseline) & $4 / 374$ & 1.0 & - \\
\hline Possibly significant & $2 / 165$ & 1.0 & 0.2 to 5.7 \\
\hline Significant & $24 / 966$ & 2.4 & 0.8 to 6.9 \\
\hline Not recorded & $26 / 1789$ & & \\
\hline \multicolumn{4}{|l|}{ Perioperative variables } \\
\hline \multicolumn{4}{|l|}{ Grade of surgeon } \\
\hline Others (baseline) & $10 / 332$ & 1.0 & - \\
\hline Consultant & $40 / 2299$ & 0.6 & 0.3 to 1.1 \\
\hline Unknown & $6 / 663$ & & \\
\hline \multicolumn{4}{|l|}{ Number of valves implanted } \\
\hline Single (baseline) & $49 / 2453$ & 1.0 & - \\
\hline Multiple & $7 / 841$ & 0.4 & 0.2 to 1.0 \\
\hline Total cross clamp time (per $15 \mathrm{~min}$ ) & $27 / 1675$ & 0.8 & 0.6 to 0.95 \\
\hline \multicolumn{4}{|l|}{ Complications } \\
\hline None/not significant & $34 / 2015$ & 1.0 & - \\
\hline Possibly significant/significant & $8 / 285$ & 2.3 & 1.1 to 5.0 \\
\hline Unknown & $14 / 938$ & & \\
\hline \multicolumn{4}{|l|}{ Postoperative variables } \\
\hline \multicolumn{4}{|l|}{ Postoperative complications } \\
\hline None/not significant (baseline) & $16 / 1191$ & 1.0 & - \\
\hline Possibly/significant & $29 / 1401$ & 1.8 & 1.0 to 3.4 \\
\hline Unknown & $11 / 702$ & & \\
\hline \multicolumn{4}{|l|}{ Presence of pacemaker } \\
\hline No (baseline) & $40 / 2438$ & 1.0 & - \\
\hline Yes & $5 / 174$ & 2.0 & 0.8 to 5.1 \\
\hline Unknown & $11 / 682$ & & \\
\hline Hospital duration in weeks & $45 / 2659$ & 0.8 & 0.5 to 1.1 \\
\hline Pulse (per 10 beats/min) & $27 / 1341$ & 0.9 & 0.7 to 1.2 \\
\hline \multicolumn{4}{|l|}{ Rhythm (post operative) } \\
\hline Sinus rhythm/regular rhythm (baseline) & $26 / 1467$ & 1.0 & - \\
\hline Atrial fibrillation/abnormal rhythm & $18 / 947$ & 1.4 & 0.7 to 2.5 \\
\hline Unknown & $12 / 880$ & & \\
\hline \multicolumn{4}{|l|}{ Rhythm (at discharge) } \\
\hline Sinus rhythm/regular rhythm (baseline) & $15 / 839$ & 1.0 & - \\
\hline Atrial fibrillation/abnormal rhythm & $22 / 1002$ & 1.6 & 0.8 to 3.2 \\
\hline Unknown & $19 / 1453$ & & \\
\hline Systolic arterial blood pressure (per $10 \mathrm{~mm} \mathrm{Hg}$ ) & $25 / 1275$ & 1.0 & 0.7 to 1.2 \\
\hline Diastolic arterial blood pressure (per $10 \mathrm{~mm} \mathrm{Hg}$ ) & $25 / 1274$ & 1.2 & 0.8 to 1.8 \\
\hline
\end{tabular}

${ }^{\star}$ Graded as non-significant, aortic: $<30 \mathrm{~mm} \mathrm{Hg}$, mitral: $<2 \mathrm{~mm} \mathrm{Hg}$; possibly significant, aortic 30-50 mm Hg, mitral: 3-5 mm Hg; and significant, aortic: $>50 \mathrm{~mm} \mathrm{Hg}$, mitral: $>5 \mathrm{~mm} \mathrm{Hg}$, baseline: non-significant. The not recorded category includes a category where measurements were taken.

Clinical records were completely missing for $16 \%$ of the valves, with a large proportion destroyed in accordance with the implantation centre's record storage policy. These valves tended to be in older, now deceased patients with earlier implantation surgery dates.

The average age at valve implantation of the study cohort was 54 years with $55 \%$ of the valves implanted in the mitral, $44 \%$ in the aortic, and $0.2 \%$ in the tricuspid position. Fifty six OSFs were observed as of 31 July 1997, with 43 occurring in mitral and 13 in aortic valves. One mitral OSF had an opening angle of $70^{\circ}$. The overall OSF rate was $0.17 \%$ (95\% confidence intervals (CI) 0.13 to 0.22 ) a year. Cumulative risk (\%) of OSF increased for approximately 11 years and remained constant thereafter for mitral valves (fig 1). In contrast, for the aortic valves the risk was zero for the first three years after implantation but appeared to rise during the remainder of the follow up period. A total of $312(22 \%$ of total deaths, incidence rate $0.95 \% /$ year) acute deaths occurred, of which 115 had inadequate information on the cause. Of the 115 deaths five were thought to have a strong possibility of being related to OSF and a further 17 were deemed to be less likely to be related to OSF, but the possibility could not be absolutely ruled out. There were seven OSF events (OSF rate $0.18 \%$ ) among valves with completely missing clinical records.

Univariate regression analyses found significant associations between the risk of OSF and age at implantation, valve size, valve position, year of manufacturing, welder identity, and shop order fracture rate (table 1). After adjustment for the effects of age the following variables were found to be significantly associated with the risk of OSF: body surface area (BSA), left ventricular systolic pressure, cross clamp time during surgery, and multiple valve implants (table 2). Additionally, associations with underlying valvar disease, type of surgery (elective versus emergency), concomitant surgery, and postoperative drugs (grouped as antihypertensive, $\beta$ blockers, and antiarrythmics) were investigated. Some of these factors were used as surrogates for a patient's general health, level of physical activity, hypertension, and arrhythmia. No significant associations were found with these factors.

In the multiple regression analysis the 21 and $25 \mathrm{~mm}$ sizes were combined to overcome the problem of small numbers and because these valves appeared to have a low risk of OSF (tables 1 and $3^{3}$ ). Age at implantation, BSA, cross clamp time during surgery, valve size, shop order fracture rate, and manufacturing period were significantly related to OSF in the multiple regression analysis. However, information on cross clamp time was missing for more than $50 \%$ of the OSF events and therefore the observed association with this factor is not discussed any further.

Results from a regression analysis including all significant predictors that had information on all OSF events show a $4 \%(95 \%$ CI $2 \%$ to $6 \%$ ) decrease in the risk of OSF for a one year increase in age at implantation (table 3 ). RR of 8 and 13 were observed for 31 and $33 \mathrm{~mm}$ valves, respectively, and a fivefold increase was observed for $23 \mathrm{~mm}$ valves relative to $\leqslant 21$ and $25 \mathrm{~mm}$ valves. Valves manufactured between 1981 and 1984 showed a high risk of experiencing OSF relative to those manufactured before 1981 (RR 4.4, 95\% CI 1.6 to 12.3). There was a $40 \%(95 \%$ CI $20 \%$ to $50 \%)$ increase in the risk of OSF for a unit increase in shop order fracture rate.

Including BSA in the regression analyses showed a fivefold (95\% CI 2 to 13) increase in the risk of OSF for a $0.5 \mathrm{~m}^{2}$ increase in BSA. The mean BSA for patients with valves experiencing an OSF was $1.8 \mathrm{~m}^{2}$ compared with 
Table 3 Results from multiple regression analyses

\begin{tabular}{|c|c|c|c|}
\hline Variables & Relative risk & $95 \% C I$ & $p$ Value \\
\hline \multicolumn{4}{|c|}{$\begin{array}{l}\text { Relative risk of OSF from a model including only significant predictors (excluding BSA, based on valves } \\
\text { with complete serial numbers; } n \text { of } O S F=56 \text { ) }\end{array}$} \\
\hline Age at implantation (in years) & 0.96 & 0.94 to 0.98 & $<0.001$ \\
\hline \multicolumn{4}{|l|}{ Valve size } \\
\hline$\leqslant 21$ and 25 & 1.0 & - & 0.004 \\
\hline 23 & 5.5 & 1.1 to 26.4 & \\
\hline 27 & 4.2 & 0.8 to 20.1 & \\
\hline 29 & 4.4 & 1.0 to 20.7 & \\
\hline 31 & 8.5 & 1.9 to 37.4 & \\
\hline 33 & 13.5 & 2.5 to 71.4 & \\
\hline Shop order fracture rate & 1.4 & 1.2 to 1.5 & $<0.001$ \\
\hline \multicolumn{4}{|l|}{ Manufacturing date } \\
\hline Before 1981 & 1.0 & - & $<0.001$ \\
\hline $1981-1984$ & 4.4 & $1.6-12.3$ & \\
\hline \multicolumn{4}{|c|}{$\begin{array}{l}\text { Relative risk of OSF from a model including only significant predictors (based on valves with complete } \\
\text { serial numbers and known BSA; } n \text { of } O S F=34 \text { ) }\end{array}$} \\
\hline Age at implantation (in years) & 0.97 & 0.94 to 1.0 & 0.057 \\
\hline $\mathrm{BSA}\left(0.5 \mathrm{~m}^{2}\right)$ & 5.3 & 2.1 to 13.1 & $<0.001$ \\
\hline Valve size & & & 0.02 \\
\hline$\leqslant 21$ and 25 & 1.0 & - & \\
\hline 23 & 3.2 & 0.6 to 17.6 & \\
\hline 27 & 2.6 & 0.5 to 14.5 & \\
\hline 29 & 2.2 & 0.4 to 12.0 & \\
\hline 31 & 6.4 & 1.4 to 29.6 & \\
\hline 33 & 12.0 & 1.9 to 74.6 & \\
\hline Shop order fracture rate & 1.4 & 1.2 to 1.6 & $<0.001$ \\
\hline \multicolumn{4}{|l|}{ Manufacturing date } \\
\hline Before 1981 & 1.00 & & 0.006 \\
\hline $1981-1984$ & 5.0 & 1.2 to 21.0 & \\
\hline
\end{tabular}

BSA, body surface area.

$1.7 \mathrm{~m}^{2}$ for patients with non-OSF valves. BSA was not found to be strongly correlated with valve size and on average was higher for men than for women, and for aortic valve patients than for mitral patients. The association between BSA and the risk of OSF remained significant even after adjustment for these factors.

To check the robustness of the results obtained, additional analyses were performed by including valve position, which is highly correlated with valve size, in the final model, by replacing age at implantation with current age, and by excluding valves of patients who died within 30 days of implantation surgery. These additional analyses had very little effect on the results.

Table 4 Relative risk of OSF by follow up time

\begin{tabular}{|c|c|c|c|}
\hline Risk factors & Relative risk & $95 \% C I$ & $p$ Value \\
\hline \multicolumn{4}{|c|}{ Follow up until 31 December 1989, 37 OSF } \\
\hline Age (in years) & 0.96 & 0.94 to 0.99 & 0.004 \\
\hline Valve size & & & 0.005 \\
\hline$\leqslant 21$ and 25 & 1.00 & - & \\
\hline 23 & 4.6 & 0.5 to 43.9 & \\
\hline 27 & 4.2 & 0.4 to 40.3 & \\
\hline 29 & 4.7 & 0.5 to 40.0 & \\
\hline 31 & 12.2 & 1.6 to 95.1 & \\
\hline 33 & 18.0 & 2.0 to 166.7 & \\
\hline Manufacturing period & & & 0.02 \\
\hline Before 1981 (baseline) & 1.0 & - & \\
\hline $1981-1984$ & 9.7 & 1.5 to 63.8 & \\
\hline Shop order fracture rate & 1.4 & 1.2 to 1.60 & $<0.001$ \\
\hline \multicolumn{4}{|c|}{ Follow up 1 fanuary 1990 to 31 fuly 1997, 19 OSF } \\
\hline Age (in years) & 0.95 & 0.92 to 0.98 & 0.004 \\
\hline \multicolumn{4}{|l|}{ Valve size } \\
\hline$\leqslant 21$ and 25 & 1.00 & - & 0.55 \\
\hline 23 & 6.2 & 0.7 to 56.0 & \\
\hline 27 & 4.1 & 0.4 to 39.8 & \\
\hline 29 & 3.9 & 0.4 to 36.7 & \\
\hline 31 & 7.0 & 0.4 to 35.4 & \\
\hline 33 & 6.7 & 0.4 to 111.8 & \\
\hline \multicolumn{4}{|l|}{ Manufacturing period } \\
\hline Before 1981 (baseline) & 1.0 & - & 0.21 \\
\hline $1981-1984$ & 2.6 & 0.6 to 11.2 & \\
\hline Shop order fracture rate & 1.3 & 1.1 to 1.7 & 0.011 \\
\hline
\end{tabular}

A significant interaction was observed between valve size and follow up time, indicating that the association between size and OSF was not constant over time. In the analysis the follow up time was therefore divided into date of first known UK implantation of BSCC valves (1989-the first 10 years) and the period thereafter (1990 to 31 July 1997). BSA was not included in this analysis as it was available for only a small number of OSF events after 1989 . Valve size was strongly related to the risk of OSF during the first follow up period and the association weakened considerably thereafter (table 4). RR estimates in the post-1989 period for 31 and $33 \mathrm{~mm}$ sized valves decreased substantially and that for $23 \mathrm{~mm}$ valves increased relative to the pre-1990 period. However, the CIs for the estimates of the RR are wide because of the small number of events observed and they overlap between the two time periods. Including valve position in the models produced RRs comparing mitral with aortic valves of 2.8 (95\% CI 0.5 to 15.3 ) and 0.6 (95\% CI 0.1 to 2.6$)$ in the pre-1990 and post-1989 periods, respectively (not presented in the table). Investigation of crude OSF rates by valve position supported this finding (crude rate of mitral OSF was $0.31 \%$ before 1990 and $0.15 \%$ from 1990 onwards; corresponding figures for aortic valves were $0.06 \%$ and $0.12 \%$ ). Reports on three additional aortic (two $23 \mathrm{~mm}$ and one $25 \mathrm{~mm}$ ) and two mitral (31 mm) OSF events were received after the closing date of this study and were not included in the analyses.

\section{Discussion}

The UK cohort study of BSCC patients differs from other studies with respect to the large size of the study population, length of follow up, and focus on patient characteristics. Previous studies conducted elsewhere in Europe focus mainly on valve characteristics and risks of OSF of $70^{\circ}$ valves $^{2-4}$ or large $60^{\circ}$ mitral valves. ${ }^{7}$ Almost all of the UK implants were $60^{\circ}$ valves, the most common BSCC valve implanted worldwide, with a broad distribution across valve sizes. This study has enabled an examination of risks across an 18 year period and a detection of changing patterns of OSF over time.

The overall crude OSF rate of $0.17 \% /$ year in the UK exceeds the rates for both Sweden $(0.14 \%)^{13}$ and the Netherlands $(0.12 \%)^{14}$ for $60^{\circ}$ valves. Reasons for higher OSF rates in the UK are partly related to the higher percentage of large sized mitral valve replacements. There is a possibility that a proportion of OSF cases remain undetected worldwide. Swedish ${ }^{2}$ and Dutch $^{15}$ studies have suggested under reporting rates for OSF of $21 \%$ and $26 \%$ (for $60^{\circ}$ valves), respectively. In the UK the under reporting rate is thought to be at least $10 \%$.

\section{PATIENT CHARACTERISTICS}

Similar to other epidemiological studies of patients with BSCC valves, ${ }^{35}$ age at implantation was found to be the strongest patient related predictor of OSF, with risk falling with advancing age. The reasons for this age effect 
may be higher levels of physical activity among younger patients, placing greater haemodynamic stresses across the implanted valve, ${ }^{16}$ and lower postmortem rates in older patients $(25 \%$ for $\geqslant 59$ years and $42 \%$ for $<50$ years in the $\mathrm{UK})^{17}$ leading to greater under reporting of OSF events in this group. BSA was found to be strongly associated with OSF and confirms the finding of Walker and colleagues. ${ }^{5}$ The resultant higher cardiac output among those with large body size may be responsible for this excess risk.

Missing clinical information resulted in a loss of statistical power but is unlikely to have introduced bias in studying the risk of OSF in relation to patient characteristics. One of the limitations of this study is that current information on patient characteristics is not available. Some characteristics such as blood pressure, cardiac rhythm, and BSA may change over time. Many patients were no longer followed up at the implantation centres and investigations such as cardiac catheterisations are not performed routinely following implantation surgery. Therefore longer term postoperative data on these factors are less complete.

VALVE SIZE AND POSITION

Risk of OSF increased 13-fold in $33 \mathrm{~mm}$, eightfold in $31 \mathrm{~mm}$, and fivefold in $23 \mathrm{~mm}$ compared with $\leqslant 21 \mathrm{~mm}$ and $25 \mathrm{~mm}$ valves. However, this association changed over time with risk associated with $31-33 \mathrm{~mm}$ valves decreasing substantially, but the same pattern was not seen for $23 \mathrm{~mm}$ valves. The majority of $31-33 \mathrm{~mm}$ valves were implanted in the mitral position and almost all $23 \mathrm{~mm}$ valves in the aortic position, hence to some extent trends with valve size reflect trends in valve position. This is supported by the finding of increased risks of OSF for mitral valves relative to aortic valves during the early part of the follow up time in this study and a reverse pattern observed in more recent years. After the closing date of 31 July 1997 of the UK cohort, five OSF events were reported, including three aortic OSFs.

Possible reasons for changing patterns of OSF rates were considered. One reason is the prophylactic explantation of a greater number of large mitral valves in the UK, which has contributed to the decrease in mitral OSF rates (23 mitral versus seven aortic). Some of these explanted valves were identified to have a single leg separation, a possible precursor to OSF, in screening programmes set up especially for patients with large mitral valves. ${ }^{18} \mathrm{~A}$ second reason may be that instantaneous death almost always associated with aortic OSFs may lead to a greater degree of under reporting among these valves worldwide. ${ }^{319}$ Only one patient with aortic compared with 16 patients with mitral OSFs survived long enough to undergo emergency explantation surgery in the UK. The postmortem rate for UK patients with BSCC valves is $30 \%$ for all deaths and $49 \%$ for acute deaths. Furthermore, patients in the UK are tracked by the Office of National Statistics and Central Services Agency for information on their vital status and death certificates are forwarded for systematic review. Long term follow up combined with almost half of all acute deaths being investigated by postmortem examination may have resulted in the detection of a greater number of aortic OSFs in the UK. An increased OSF rate among $23 \mathrm{~mm}$ aortic valves has been reported in Sweden, ${ }^{2}$ where the rate of postmortem examination is high $(75 \%$ of all and acute deaths), but not in the Netherlands where the rate of postmortem examination is $l_{0}{ }^{315}$ (9\% excluding operative deaths and $17 \%$ of all deaths), or in the USA $^{6}$ where patient follow up is less complete. Thus OSF rates in aortic valves may be greater than previously recognised.

SHOP ORDER AND MANUFACTURING PERIOD An increased risk of OSF was observed in relation to the OSF rate among other valves manufactured in the same batch and for valves manufactured between 1981 and 1984. These findings are in line with those reported in other studies. ${ }^{78}$ Changes made in the manufacturing process in April 1984 have been considered as a possible reason why no OSF events have been reported worldwide in valves manufactured after this period. ${ }^{6}$

\section{SUMMARY}

The UK study has identified age and body size as key patient factors for the risk of OSF and confirmed the findings of shop order fracture rate and manufacturing period as risk factors. With respect to valve size and position, previous studies have reported risks associated with large mitral valves. The current guidelines for prophylactic explantation place patients with large mitral valves, welded by a specific group of welders, between January 1981 and June 1982 at the highest risk of OSF. ${ }^{10}$ However, the UK study has shown an excess risk among $23 \mathrm{~mm}$ aortic valves, emphasising that the problem is not limited to patients with large mitral valves, particularly in the past 10 years. This phenomenon has not been identified previously and clearly highlights the need for continued monitoring of patients with BSCC heart valves, and it should be taken in to account in determining suitability of patients for valve explantation surgery. As OSF events have continued to be reported through recent years, clinicians should continue to advise their patients of the need for vigilance in recognising early signs of valve malfunction, regardless of the implanted BSCC valve position.

\section{Appendix}

CLASSIFICATION OF DEATHS

All patients with BSCC valves in the UK are tracked by either the Office of National Statistics or the Central Services Agency. At the beginning of the study in 1992 the names and dates of birth were submitted to these agencies for flagging. Death certificates were sent to the Hammersmith Hospital for retrospective review and from 1992 onwards the registry staff have received the death certificates for patients with BSCC valves as deaths occur. All postmortem reports are requested for review irrespective of the cause of death. 
In the absence of a postmortem examination, for all cardiac related deaths and for death certificates listing a single cause of death or the mode of death (cardiac failure) the certifying physician or hospital is contacted and the notes requested for review. On occasion physicians have been interviewed by telephone to discuss the circumstances leading to death. We aim to ascertain whether the death was sudden, the state of the patient's health before death, and whether the death was witnessed. For patients who died in hospital chest $x$ rays and other investigation reports may be requested.

Where no further or inadequate information is available surrounding the patient's death, (usually because of missing records or destroyed records of patients who died more than 10 years ago) the deaths are classified according to the place and causes of death. The causes of death are reviewed for matches with any of the following recorded causes of death on the death certificates of known OSF patients: myocardial infarction; pulmonary oedema; cerebral anoxia; acute left ventricular failure; left ventricular failure; (acute) cardiac failure; mitral/aortic incompetence; acute heart failure; cardiogenic shock; right and left ventricular failure; coronary thrombosis; congestive cardiac failure.

The place of death was also investigated. If the patient died within a hospital, particularly a cardiac centre, the death was deemed to be less likely to be related to OSF than if the patient had died suddenly at home. This review was undertaken in an attempt to estimate the degree of under reporting of OSF events in the UK.

Of the 115 acute deaths, it is the opinion of the UK research team that five deaths that occurred before 31 July 1997 had a strong possibility of being related to OSF; all patients shared common causes of death with known OSF patients and died at home. A further 17 patients had less acute recorded causes of death (still matching OSF events) and died as inpatients soon after admission. The remaining patients all died in hospital and the recorded causes of death did not match those for known OSF events.

The study was supported by a grant from the Bowling Pfizer Heart Valve Settlement Fund. We are grateful to Sir Donald Acheson, Professor Patrick Royston, and the Bowling Pfizer Trustees for their advice. We thank Caitlin Whitworth of MedicAlert for her help in tracing patients, Mr Chandi Ratnatunga and $\mathrm{Mr}$ Bruce Keogh for the review of death certificates, and the cardiothoracic consultants, cardiologists and medical records departments of Aberdeen Royal Infirmary, AMI Alexande
Cheshire, Bristol Royal Infirmary Bristol, The Cardiothoracic Centre Liverpool NHS Trust Liverpool, Children's Hospital Birmingham, Edinburgh Royal Infirmary, Freeman Hospital Newcastle upon Tyne, Glasgow Royal Infirmary, Guys Hospital London, Hammersmith Hospital London, Humana Wellington Hospital London, Kings College Hospital London, Leeds General Infirmary, London Chest Hospital London, Manchester Royal Infirmary, Northern General Sheffield, Papworth Hospital Cambridge, Queen Elizabeth Hospital Birmingham, Royal Brompton Hospital London, Royal Hospital for Sick Children Glasgow, Royal London Hospital, Royal Victoria Hospital Belfast, Southampton General Hospital, St George's Hospital London, St Mary's Hospital London, St Thomas's Hospital London, The Hospital for Children Great Ormond Street London, The Harley Street Chidren Great Ormond Street London, The Harley Street Clinic London, The John Radcliffe Hospital Oxford, Victoria Hospital Blackpool, Wals-
grave Hospital Coventry, Wythenshawe Hospital Manchester, grave Hospital Coventry, Wyth

1 Björk VO. The improved Björk-Shiley tilting disc valve prosthesis. Scand F Thorac Cardiovasc Surg 1978;12:81-4.

2 Lindblom D, Rodriguez L, Björk VO. Mechanical failure of the Björk-Shiley valve. $\mathcal{F}$ Thorac Cardiovasc Surg 1986;92: 894-907.

3 Van der Graaf Y, De Waard F, Van Herwerden, et al. Risk of trut fracture of Björk Shiley valves. Lancet 1992;339:25761

4 Ericsson A, Lindblom D, Semb G, et al. Strut fracture with Björk-Shiley 70 degree convexo-concave valves. An international multi-institutional study. Eur f Cardiothorac Surg 1992;6:339-46.

5 Walker AM, Funch DP, Sulsky SI, et al. Patient factors associated with strut fracture in Björk-Shiley 60 degree convexo-concave heart valves. Circulation 1995;92:3235-9.

6 Walker AM, Funch DP, Sulsky SI, et al. Manufacturing characteristics associated with strut fracture in Björk-Shiley 60 degree convexo-concave heart valves. I Heart Valve Dis 1995;4:640-8.

7 Kallewaard M, Algra A, Defauw J, et al. Which manufacturing characteristics are predictors of outlet strut fracture in ing characteristics are predictors of outlet strut fracture in large 60-degree Björk-Shiley Convexo-Concave
valves? F Thorac Cardiovasc Surg 1999;117:766-74

8 Walker AM, Funch DP, Bianchi L, et al. Shoporder fracture rate as a risk factor in Björk-Shiley CC60 degree heart valves. F Heart Valve Dis 1997;6:264-7.

9 Kallewaard M, Van de Graaf Y. Welder identity weld date and the risk of outlet strut fracture in Björk-Shiley convexo-concave heart valves. Heart 1996;76:510-2.

10 Supervisory Panel for the Bowling Pfizer Heart Valve Settlement Fund. Guidelines to assess patients with Björk-Shiley convexo-concave heart valves for elective explantation. Report submitted to US federal court 1997.

11 Collett D. Modelling survival data in medical research. London: Chapman and Hall, 1994

12 Altman D. Practical statistics in medical research. London: Chapman and Hall, 1991.

13 Lindblom D, Rodriguez L, Björk VO. Mechanical failure of the Björk-Shiley valve. Updated follow up and considerations on prophylactic replacement. $\mathcal{F}$ Thorac Cardiovasc Surg 1989;97:95-7.

14 Kallewaard M. Björk-Shiley convexo-concave heart valvesthe risk of outlet strut fracture and clinical implications [dissertation]. Julius Centre for Patient Oriented Research, Utrecht, the Netherlands, 1997:43-5.

15 Kallewaard M, Algra A, Defauw J, et al. Likelihood of underreporting of outlet strut fracture from examination of the Dutch Björk-Shiley CC cohort. Am f Cardiol 1998;82: $768-73$.

16 Glower DD, White WD, Hatton AC, et al. Determinants of reoperation after 960 valve replacements with CarpentierEdwards prosthesis. $\mathcal{F}$ Thorac Cardiovasc Surg 1994;107: 381-93.

17 Morton L, Omar RZ, Carroll S, et al. Incomplete and inaccurate death certification: the impact on research. $\mathcal{7}$ Public curate death certification: the

18 O'Neil WW, Chandler JG, Gordon RE, et al. Radiographic detection of strut separations in Björk-Shiley convexoconcave mitral valves. N Engl f Med.1995;333:414-9.

19 de Mol BA, Kallewaard M, McLellan RB, et al. Single-leg strut fractures in explanted Björk-Shiley valves. Lancet 1994;343:9-12 